\title{
Linfoma de Burkitt como adenopatía axilar en un paciente inmunosuprimido
}

Burkitt lymphoma as an axillary adenopathy in an immunosuppressed patient

Hélio Martins, David Paiva, Margarida Cerqueira, Jorge Cotter

Department of Internal Medicine. Hospital da Senhora da Oliveira - Guimarães, Braga, Portugal

\begin{abstract}
Burkitt lymphoma is derived from germinal or post-germinal center B cells and is a highly aggressive B cell non-Hodgkin lymphoma that represents $<1$ percent of adult non-Hodgkin lymphomas. The authors describe the case of a 63 years old Caucasian male, with history of human immunodeficiency virus infection, latent syphilis and varicella zoster infection on the left limb (L3 dermatome) who came to the emergency department with a palpable left axillary mass with three weeks evolution accompanied with vesicles 48 hours after. He reported a history of anorexia and weight loss on the past 3 months. Complete blood count was within normal range but was observed a fivefold elevation of lactate dehydrogenase and a CD 4 count $<200 \mathrm{cells} / \mathrm{microL}$. The histology of the adenopathic axillar conglomerate made the diagnosis of Burkitt lymphoma but, besides all efforts, the patient ended to die before starting a regimen of chemotherapy.
\end{abstract}

Keywords: Burkitt lymphoma, HIV, axillary adenopathy

Palabras clave: Adenopatía axilar, Linfoma de Burkitt, Virus de la Inmunodeficiencia Humana

\section{INTRODUCTION}

Burkitt lymphoma (BL) is derived from germinal or post-germinal center $B$ cells and is a highly aggressive $B$ cell nonHodgkin lymphoma characterized by the translocation and deregulation of the MYC gene on chromosome $8^{1}$. It represents $<1$ percent of adult non-Hodgkin lymphomas. There are three different clinical variants: endemic, sporadic and immunodeficient BL. The last variant is typically observed in the setting of human immunodeficiency virus infection and in patients with CD4 counts exceeding 200cells/microL2.
The typical clinical presentation in the adult patients is an extranodal disease, and the abdomen is the most frequent site of involvement. The diagnosis is based on the pathologic evaluation of the tumour mass and the lymphoma tumour cells generally strongly express markers of $B$ cell differentiation (CD20, CD22,CD19), as well as CD10 and BCL6. The high mitotic activity of Burkitt lymphoma is confirmed by nearly $100 \%$ of the cells staining positive for Ki67².

Fig. 1

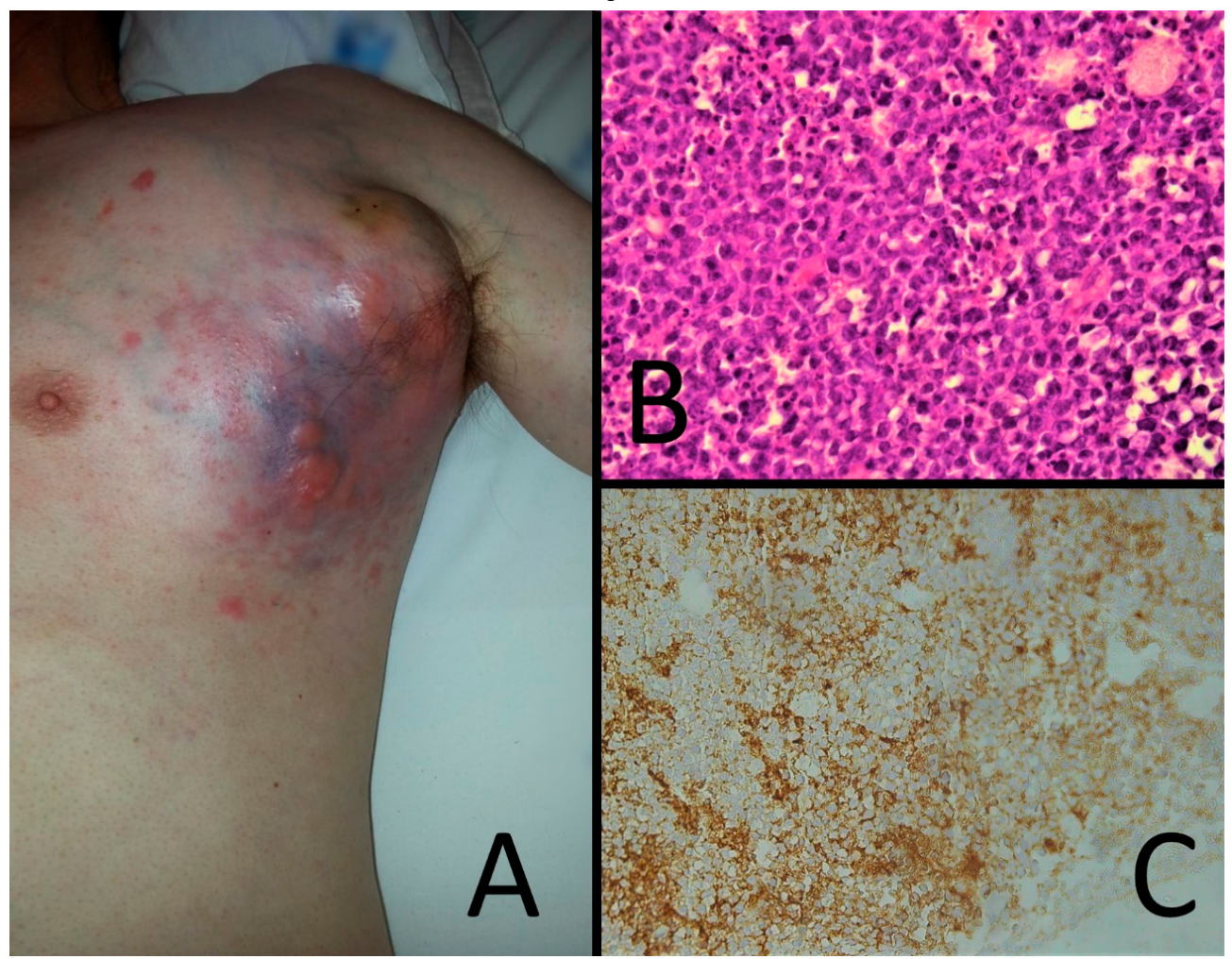




\section{CASE DESCRIPTION}

A 63 years old Caucasian male, with history of human immunodeficiency virus infection, latent syphilis and varicella zoster infection on the left limb (L3 dermatome) came to the emergency department with a palpable left axillary mass with three weeks evolution accompanied with vesicles 48hours after. He reported a history of anorexia and weight loss on the past 3 months. Complete blood count was within normal range but was observed a fivefold elevation of lactate dehydrogenase and a CD4 count <200cells/microL.

He was admitted and initiated acyclovir $10 \mathrm{mg} / \mathrm{kg}$ three times a day for 14days.

Bone marrow aspiration and biopsy, as well as cerebrospinal fluid (CSF) evaluation showed no infiltration by atypical lymphoid cells. Computerized tomography (CT) scans of the chest, abdomen, and pelvis was performed showing multiple periaortic, periceliac and small gastric curvature adenomegalies, the biggest ones with $2.8 \mathrm{~cm}$ and a voluminous mass on the left axillary space, extending to the left dorsal region, with $12.5 \times 10.1 \mathrm{~cm}$ on the transversal plan.

A Biopsy of the adenopathic axillar conglomerate (Fig. 1A) was made and demonstrated effacement of the normal architecture by sheets of atypical lymphoid cells (Fig. 1B) and immunophenotype profile CD20+ (Fig 1. C), CD79a+, CD3-, CD10+, CD23-, bcl-6+ and ki67+ superior to $90 \%$.

The diagnosis of $B \mathrm{~L}$ was made but, besides all efforts, the patient ended to die before starting a regimen of chemotherapy.

\section{DISCUSSION}

In the case presented, the patient had a CD4 count $<200$ cells/microL and a nodal disease, being rare as a presentation of an immunodeficient BL. But because of its aggressiveness and representing less than $1 \%$ of adult nonHodgkin lymphomas, clinical suspicion of Burkitt Lymphoma is imperative.

The differential diagnosis for BL includes other types of non-Hodgking lymphoma or tumours that can present as abdominal masses.

The treatment for $\mathrm{BL}$ requires intensive, frequent multi-agent chemotherapy with adequate CNS prophylaxis. BL is fatal if left untreated. In adult patients, prompt treatment can be associated with complete remission rates of $75 \%$ to $90 \%$ and overall survivals reaching $50 \%$ to $70 \%$ in adults ${ }^{3}$.

When the clinical suspicion of Burkitt Lymphoma is high, no delays in the confirmatory diagnosis should be permitted as the outcome depends on the prompt chemotherapy initiation

\section{REFERENCES}

1. Swerdlow SH, Campo E, Pileri SA, et al. The 2016 revision of the World Health Organization classification of lymphoid neoplasms. Blood. 2016; 127:2375.

2. Armitage JO, Weisenburger DD. New approach to classifying non-Hodgkin's lymphomas: clinical features of the major histologic subtypes. Non-Hodgkin's Lymphoma Classification Project. J Clin Oncol. 1998; 16:2780.

3. Blum KA, Lozanski G, Byrd JC. Adult Burkitt leukemia and lymphoma. Blood. 2004; 104:3009. 